\title{
Disparities in Health Insurance Coverage and Access to Care by English Language Proficiency in the USA, 2006-2016
}

\author{
Tianyi Lu, $P h D^{7}$ and Rebecca Myerson, $P h D^{2}$ (i) \\ 'University of Southern California (USC) School of Pharmacy and Leonard D. Schaeffer Center for Health Policy and Economics, Los Angeles, CA, \\ USA; ${ }^{2}$ University of Wisconsin School of Medicine and Public Health, Madison, WI, USA.
}

BACKGROUND: In the USA, people with limited English proficiency (LEP) disproportionately experience gaps in health insurance coverage and access to care. The Patient Protection and Affordable Care Act (ACA) of 2010 included reforms that could improve these outcomes.

OBJECTIVE: To describe changes in insurance coverage and access to health care by English language proficiency over 2006-2016.

DESIGN: We used regression models to estimate changes in coverage and access after 2010 for adults with high vs. limited English proficiency, adjusting for socio-economic status, demographic characteristics, and health care needs. We used difference-in-differences models to assess adjusted changes in disparities by English proficiency after 2010. Supplemental analyses used nearestneighbor propensity score matching to balance the characteristics of respondents.

PARTICIPANTS: Respondents aged 18-64 in the Medical Expenditure Panel Survey over 2006-2016, with high ( $n=$ $174,214)$ or limited ( $n=16,484)$ English language proficiency. MAIN MEASURES: Insurance coverage was a binary variable indicating any health insurance coverage during the past 12 months. Access to care was measured using binary variables indicating whether the respondent had a usual source of care and received necessary medical, dental, and preventive care.

KEY RESULTS: Gains in health insurance coverage after 2010 were significant for adults with high English proficiency (1.7 percentage points, $p<0.001$ ) and adults with limited English proficiency (4.6 percentage points, $p=0.007$ ); gains did not significantly vary by English proficiency. Adults with LEP showed larger improvements than adults with high English proficiency in having a usual source of care (5 percentage points, $p=0.007$ ) and receiving needed medical care and dental care (1.4 percentage points, $p=0.013$, and 2.8 percentage points, $p=0.009$, respectively). Findings remained similar when matching was used to balance the

The research was previously presented at the Population Association of America Meeting on April 14, 2019 and the International Society for Pharmacoeconomics and Outcomes Research (ISPOR) annual conference on May 22, 2019.

Electronic supplementary material The online version of this article (https://doi.org/10.1007/s11606-019-05609-z) contains supplementary material, which is available to authorized users.

Received July 7, 2019

Revised October 15, 2019

Accepted December 6, 2019

Published online January 2, 2020 measured characteristics of respondents with high vs. limited English proficiency.

CONCLUSIONS: Disparities in health care access by English proficiency narrowed after 2010, the year of passage of the ACA.

KEY WORDS: English proficiency; disparities; health policy; health insurance; access to care.

J Gen Intern Med 35(5):1490-7

DOI: $10.1007 / \mathrm{s} 11606-019-05609-\mathrm{Z}$

(C) Society of General Internal Medicine 2020

\section{INTRODUCTION}

In 2011, 8.8\% of the US population (25.3 million people) had limited English proficiency (LEP), reporting that they speak a language other than English at home and they speak English less than "very well.". These figures are rapidly growing as the US population becomes increasingly diverse. ${ }^{2}$ LEP has been widely documented as a barrier to health care in the USA. People with LEP experience difficulties in obtaining health insurance coverage, ${ }^{3,4}$ accessing health care services, ${ }^{5-11}$ receiving good quality care with high patient satisfaction, ${ }^{12-14}$ communicating with their health care providers, ${ }^{15-19}$ using preventive health care, ${ }^{7,20-24}$, and achieving treatment adherence. ${ }^{25-28}$ People with LEP also experience worse health outcomes than those with high English proficiency, ${ }^{5,7,29}$ including undiagnosed or uncontrolled hypertension, poor glycemic control and asthma control, ${ }^{28,30,31}$ unplanned emergency room (ER) visits, ${ }^{32,} 33$ prolonged hospital length of stay, ${ }^{34,} 35$ frequent hospital readmission, ${ }^{36}$, and serious adverse effects. ${ }^{13,} 37,38$

The Patient Protection and Affordable Care Act (ACA) of 2010 was designed to expand health insurance coverage to Americans who were previously uninsured, improve access to care, and advance health equity. It included numerous provisions relevant to coverage and access for people with LEP. For example, health programs and activities receiving federal financial assistance were now required to provide meaningful access to people with LEP, and insurers in counties with large non-English-speaking populations were required to provide translations of insurance documents. ${ }^{39}$ Such requirements supplemented prior legislation such as the Civil Rights Act of 1965 and Executive Order 13166 of 2000, which prohibit 
discrimination by national origin and set standards for providing meaningful health care access. ${ }^{40}$ The ACA also provided funding to support in-person insurance assistance programs and funding for training in cultural competence. ${ }^{41}$ Additionally, the ACA revisited the national Culturally and Linguistically Appropriate Service (CLAS) standards to enhance access to appropriate services regardless of English proficiency. ${ }^{40,} 42$ These ACA provisions were implemented over time, with the earliest starting after the law's passage in $2010 .^{40}$

Given that addressing barriers to care and promoting health equity were goals of the ACA, the impacts of the ACA on this population with particularly low health care access and poor health outcomes merits study. A recent study found that disparities in patient-provider communication by English language proficiency narrowed but persisted after $2010 .{ }^{40}$ However, little is known about how health insurance coverage and access to health care changed among individuals with LEP after the ACA.

To address this gap, the objective of this study was to assess whether the ACA was associated with improvements in insurance coverage and access to care for adults with limited English proficiency and declines in disparities in coverage and access by English language proficiency. To achieve these objectives, we used 2006-2016 data from the nationally representative Medical Expenditure Panel Survey (MEPS). MEPS is available to participants in either English or Spanish and provides interpretation services to participants preferring other languages.

\section{METHODS}

\section{Study Design}

We tested two main hypotheses. First, we hypothesized that individuals with limited English proficiency would experience improvements in coverage and access to care after the ACA. To test this hypothesis, we used multivariable regression model to compare coverage and access for people with LEP before vs. after 2010, adjusting for potential confounders.

Second, we hypothesized that pre-existing disparities by English proficiency would decline after the ACA. To test this hypothesis, we used a multivariable difference-in-differences regression model to compare the changes in gaps in health insurance coverage and access between individuals with limited vs. high English proficiency (first difference) before vs. after 2010 (second difference), after adjustment for potential confounders. In a robustness check, we used nearest-neighbor propensity score matching to balance the limited vs. high English proficiency participants on demographic, socio-economic, and health-related characteristics.

\section{Data and Study Population}

We used data from the Medical Expenditure Panel Survey (MEPS), which provides nationally representative estimates for the US civilian noninstitutionalized population. Our study included data from the annual cross-sectional MEPS surveys over 2006 through 2016. Overall response rates over these years ranged from 46.0 to $59.3 \%{ }^{43}$ The average annual response rates for the MEPS data full-year file were $57.8 \%$ in 2006-2009, compared with 51.4\% in 2010-2016, matching trends in response rates over time for many other national surveys. ${ }^{2}$ The study was approved by the University of Southern California Institutional Review Board.

The ACA was passed in 2010. While some provisions were implemented in later years, other provisions were implemented immediately. Accordingly, 2006-2009 was considered the pre-ACA period and 2010-2016 was considered the post-ACA period.

Our study focused on nonelderly (18-64 years) US-born adults and foreign-born adults who have lived in the country for more than 5 years. Following previous studies of the ACA, we selected this sample because the ACA's provisions were designed to benefit US citizens and lawful non-citizens and because people aged younger than 18 or older than 65 were less impacted by ACA coverage expansions. ${ }^{44}$

\section{Study Variables}

Our main predictor variable was limited English proficiency (LEP). We considered respondents to have LEP if they (a) reported that a language other than English was spoken in their home and (b) reported that they did not speak English well or that they were not comfortable speaking English. Our research strategy addresses changes in the MEPS questionnaire over time (see Appendix A). This strategy has been used by United States Census Bureau and the American Community Survey (ACS) to identify people with limited English-speaking ability. ${ }^{45}$

The outcomes of interest were measures of health insurance coverage and access to care. The health insurance coverage measure was a binary variable indicating whether the participant had any health insurance coverage in the past 12 months. Measures of access to care included binary variables that indicated whether the respondent had a usual source of health care and whether the respondent needed necessary care (medical, dental, or preventive care) but was unable to receive it. (Question text: "In the last 12 months, was [respondent] unable to obtain medical/dental care, tests, or treatments they or a doctor/dentist believed necessary?")

The covariates used in multivariable modeling included information on respondents' gender, age group (age 18-24, 25-34, 35-44, 45-54, and 55-64), race (non-Hispanic white, non-Hispanic black, non-Hispanic Asian, or Hispanic), marital status, educational level (less than high school degree, high school degree, college degree, or advanced degree), household income (income less than vs. above $138 \%$ federal poverty level, a cutoff relevant to eligibility for Medicaid insurance under the ACA), employment, region of residence in the USA (Northeast, Midwest, South and West), US-born citizenship, 
self-reported health (good or excellent health, vs. fair or poor health), and reporting any diagnosed chronic conditions. Categorical variables with three or more categories were modeled using multiple binary variables.

\section{Statistical Analysis}

To compare the changes on the absolute scale in health insurance coverage and access to health care between the pre- and postACA periods, we estimated multivariable linear regression models separately for adults with high English proficiency and adults with limited English proficiency. These models adjusted for the respondent's gender, age group, race and ethnicity, marital status, educational levels, household income, employment, US-born citizenship, region of residence, self-reported health, and diagnosed chronic conditions as specified above.

To estimate whether disparities in coverage and access to care by English proficiency diminished after the ACA, we used a difference-in-differences model. The coefficient of interest in this model was an interaction term between an indicator of the post-ACA period (i.e., 2010 or later) and an indicator of limited English proficiency. Heteroscedasticity robust standard errors were clustered by individual's English proficiency. ${ }^{46}$ Analyses incorporated used survey weights to account for the survey design of the MEPS. (Additional details are provided in Appendix A.)

A key assumption in differences-in-differences models is that, in the absence of the policy change, trends between the groups would have remained parallel. While the assumption is untestable, evidence of parallel trends prior to the policy change is an evidence of the plausibility of the assumption. In a supplemental analysis, we tested whether differences in trend were present prior to the ACA. These models included the same adjustment variables as the main analysis. We also plotted the raw data for adults with LEP vs. English-proficient adults to allow a visual assessment of parallel trends in these two groups prior to the ACA.

People with high vs. low English proficiency may differ in important characteristics other than English proficiency. In a robustness check, we matched respondents with high vs. limited English proficiency on propensity scores calculated using logit model of the same patient-level characteristics adjusted for in the main model (i.e., gender, age group, race and ethnicity, marital status, educational levels, household income, employment, US-born citizenship, region of residence, selfreported health, and diagnosed chronic conditions) using a nearest-neighbor matching procedure. The goal of using this matching method was to limit potential confounding by balancing the respondents with high vs. limited English proficiency on measured demographic factors, socio-economic status, and measures of self-reported health and diagnosed conditions. We assessed whether the propensity score matching had indeed resulted in balance on these factors by calculating the standardized difference between the groups on each of the covariates in the matched sample. ${ }^{47,48}$
In supplemental analyses, we assessed whether changes in disparities by English proficiency after the ACA varied by region, by income level, and by time period. First, we ran models with the data stratified the data by region (South, West, Midwest, and Northwest) and by household income (below $138 \%$ federal poverty level, and above $138 \%$ federal poverty level). Second, we ran models with additional interaction terms to assess whether disparities by LEP were further reduced after implementation of ACA coverage expansions in 2014 (additional details are included in Appendix A). Finally, we examined whether the model findings were sensitive to model specification by repeating the analysis using logit models. We presented the logit regression model results in two ways, using odds ratios and using average marginal effects. ${ }^{49}$

\section{RESULTS}

Table 1 shows the characteristics of individuals with limited vs. high English proficiency, in the MEPS data from 2006 to 2009 (pre-ACA period) and from 2010 to 2016 (post-ACA period). The proportion rates of people with LEP in the US population, as indicated using survey-weighted data, were $3.8 \%$ in $2006-2009$ and $4.2 \%$ in $2010-2016 .{ }^{1}$ In the preACA period, compared with English-proficient adults, adults with LEP were older, less educated, more likely to live in a low-income household, more likely to be married, and less likely to be employed. Adults with LEP were more likely than English-proficient adults to report fair or poor health status, but less likely to report having any chronic conditions, matching prior analyses suggesting people with LEP are more likely to be undiagnosed for prevalent conditions. ${ }^{31,50,51}$

Table 2 reports the main results. We found significant gaps in coverage and access to care by English proficiency prior to the passage of the ACA. For example, only $45.3 \%$ of respondents with limited English proficiency reported having usual source of care, compared with $73.8 \%$ of respondents with higher English proficiency. Significant improvements in these outcomes occurred after 2010, particularly among respondents with LEP. Insurance coverage increased by 4.6 percentage points $(p<0.001)$ after 2010 for respondents with LEP. Access to care also improved for respondents with LEP after 2010: the probability of foregoing any necessary health care declined by 3.5 percentage points $(p<0.001)$, of foregoing necessary medical, dental, and preventive care declined by $2.2,2.4$, and 0.8 percentage points, respectively $(p<0.001, p<0.001, p=$ 0.014 respectively), and the probability of having a usual source of care increased by 5.5 percentage points $(p<0.001)$ after 2010. Respondents with high English proficiency experienced an increase in insurance coverage by 1.7 percentage points $(p=0.007)$ after 2010 .

Reflecting these disproportionate gains in health care access among respondents with LEP, disparities in access to health care by English language proficiency significantly declined after 2010. Respondents with LEP showed larger increases 
Table 1 Characteristics of Adults Aged 18-64 with Limited vs. High English Proficiency Between the Pre- and the Post-ACA Periods

\begin{tabular}{|c|c|c|c|c|}
\hline \multirow[t]{2}{*}{ Characteristics } & \multicolumn{2}{|c|}{ Pre-ACA period (2006-2009) } & \multicolumn{2}{|c|}{ Post-ACA period (2010-2016) } \\
\hline & \multirow{2}{*}{$\frac{\begin{array}{l}\text { Adults with LEP } \\
(n=4200)\end{array}}{\%(95 \% \mathrm{CI})}$} & \multirow{2}{*}{$\begin{array}{l}\text { English-proficient adults } \\
(n=\mathbf{5 1 , 0 3 1 )}\end{array}$} & \multirow{2}{*}{$\begin{array}{l}\begin{array}{l}\text { Adults with LEP } \\
(n=12,284)\end{array} \\
\%(95 \% \mathrm{CI})\end{array}$} & \multirow{2}{*}{$\begin{array}{l}\text { English-proficient adults } \\
(n=123,183)\end{array}$} \\
\hline & & & & \\
\hline Age (years; mean) & $41.9(41.1,42.7)$ & $40.6(40.3,40.8)$ & $43.7(43.2,44.2)$ & $40.7(40.5,40.9)$ \\
\hline Sex & & & & \\
\hline $\begin{array}{l}\text { Female } \\
\text { Education }\end{array}$ & $51.4(48.9,54)$ & $50.6(50.1,51.0)$ & $52.1(50.9,53.3)$ & $50.8(50.4,51.1)$ \\
\hline $\begin{array}{l}\text { Education } \\
<\text { High school }\end{array}$ & & & & \\
\hline$<$ High school & $65.9(63.3,68.5)$ & $14.4(13.8,15.0)$ & $62.5(60.4,64.7)$ & $13.0(12.4,13.5)$ \\
\hline High school & $22.5(20.6,24.4)$ & $30.6(29.6,31.6)$ & $22.1(20.6,23.6)$ & $25.8(25.1,26.4)$ \\
\hline Some college & $10.2(8.5,11.9)$ & $44.0(42.9,45.0)$ & $14.3(12.9,15.7)$ & $50.2(49.4,50.9)$ \\
\hline$\geq$ College & $1.4(0.7,2.0)$ & $11.1(10.4,11.8)$ & $1.1(0.7,1.4)$ & $11.1(10.5,11.7)$ \\
\hline $\begin{array}{l}\text { Annual household income } \\
<138 \% \text { FPL }\end{array}$ & $41.7(37.4,46.1)$ & $16.2(15.5,16.9)$ & $41.6(38.8,44.4)$ & $17.8(17.0,18.6)$ \\
\hline Marital status & $41.1(31.4,40.1)$ & $10.2(10.5,10.3)$ & $41.0(38.8,44.4)$ & $17.8(1 / .0,18.0)$ \\
\hline Married & $63.8(59.5,68.1)$ & $52.2(51.2,53.2)$ & $60.4(57.7,63.1)$ & $49.9(48.9,50.9)$ \\
\hline Employment status & & & & \\
\hline Employed & $62.6(59.3,65.8)$ & $73.4(72.7,74.1)$ & $65.4(63.6,67.2)$ & $71.7(71.0,72.4)$ \\
\hline Self-rated general health & & & & \\
\hline Fair or poor & $19.5(17.1,21.9)$ & $10.8(10.4,11.3)$ & $19.9(18.2,21.5)$ & $10.8(10.4,11.2)$ \\
\hline Excellent, very good, or good & $80.5(78.1,82.9)$ & $89.2(88.7,89.6)$ & $80.1(78.5,81.8)$ & $89.2(88.8,89.6)$ \\
\hline Any diagnosed chronic conditions & $46.8(42.9,50.6)$ & $59.1(58.1,60.0)$ & $50.1(47.6,52.7)$ & $59.4(58.6,60.2)$ \\
\hline Region & & & & \\
\hline South & $35.7(27.4,44.0)$ & $36.4(34.8,37.9)$ & $36.4(29.8,42.9)$ & $37.3(35.7,38.9)$ \\
\hline Northeast & $13.6(10.6,16.6)$ & $18.5(17.2,19.8)$ & $15.2(12.3,18.1)$ & $18.0(16.7,19.2)$ \\
\hline West & $44.1(37.7,50.5)$ & $22.5(21.2,23.8)$ & $40.6(35.2,46.0)$ & $22.7(21.5,24.0)$ \\
\hline Midwest & $6.6(4.8,8.4)$ & $22.7(21.4,23.9)$ & $7.8(6.9,7.0)$ & $22.0(20.7,23.3)$ \\
\hline
\end{tabular}

Data source: Medical Expenditure Panel Survey (MEPS) 2006-2016. $n$ sample size, \% weighted percentage, CI confidence interval

after 2010 in having a usual source of care (4.9 percentage points, $p=0.007$ ). Respondents with LEP also showed larger declines after 2010 than respondents with high English proficiency in foregoing or any necessary care $(3.2$ percentage points, $p=0.006)$, including necessary medical care $(1.4$ percentage points, $p=0.013)$, or necessary dental care (2.8 percentage points, $p=0.009$ ).

Our findings supported the plausibility of the parallel trends assumption underlying the difference-in-differences analysis. The unadjusted data provide visual confirmation (see Appendix B). A regression-based pre-trend check did not reject the null hypothesis of zero difference between the trends at the 5\% level for any outcomes of interest. (See Appendix C.)

Propensity score matching did not substantially change the findings. Changes in disparities remained similar, except that the change in health insurance coverage became significant at the 0.05 level (3.4 percentage-point increases, $p=0.023$ ), when propensity score matching was used to balance the sample. No standard differences exceeded the cutoff of $10 \%$, suggesting the propensity score matching produced a wellbalanced sample. (See Appendix D.) ${ }^{47,48}$

Our findings were similar when data were analyzed by region and household income, or when alternate estimation methods were used. When the data were stratified by region, the findings matched the main findings in sign and significance for 16 of the 18 models. Findings in higher and lower income groups both matched the main findings in sign and significance, but the additional improvements in coverage and access were larger for low-income households. (See Appendix E.) The findings were also qualitatively unchanged when we used a logit model rather than a linear model. (See Appendix F.) $)^{49}$

\section{DISCUSSION}

The population with limited English proficiency (LEP) is rapidly growing in the USA, ${ }^{1,2}$ and people with LEP have higher uninsured rates, lower access to care, and poorer health outcomes than people with high English proficiency. ${ }^{3,}$, 7-10, ${ }^{34}$ Previously, little was known about how recent changes to the health care system under the ACA were associated with changes in coverage and access for this under-served population. This study used data from the Medical Expenditure Panel Survey (MEPS) to document changes in health insurance coverage and access to care among adults with high vs. limited English proficiency before vs. after the ACA.

We found improved access to care among individuals with LEP after the ACA, including improvements access to necessary health care and having a usual source of care; we additionally documented significant reductions in disparities in these outcomes by English proficiency. Our analysis adjusted for a number of potential confounders, and our findings were robust to the use of matching to balance the high vs. limited English proficiency samples on demographic, socio-economic, and health-related variables. Supplemental analyses further supported the robustness of findings. These data add to the growing evidence that gaps in access to care for vulnerable 


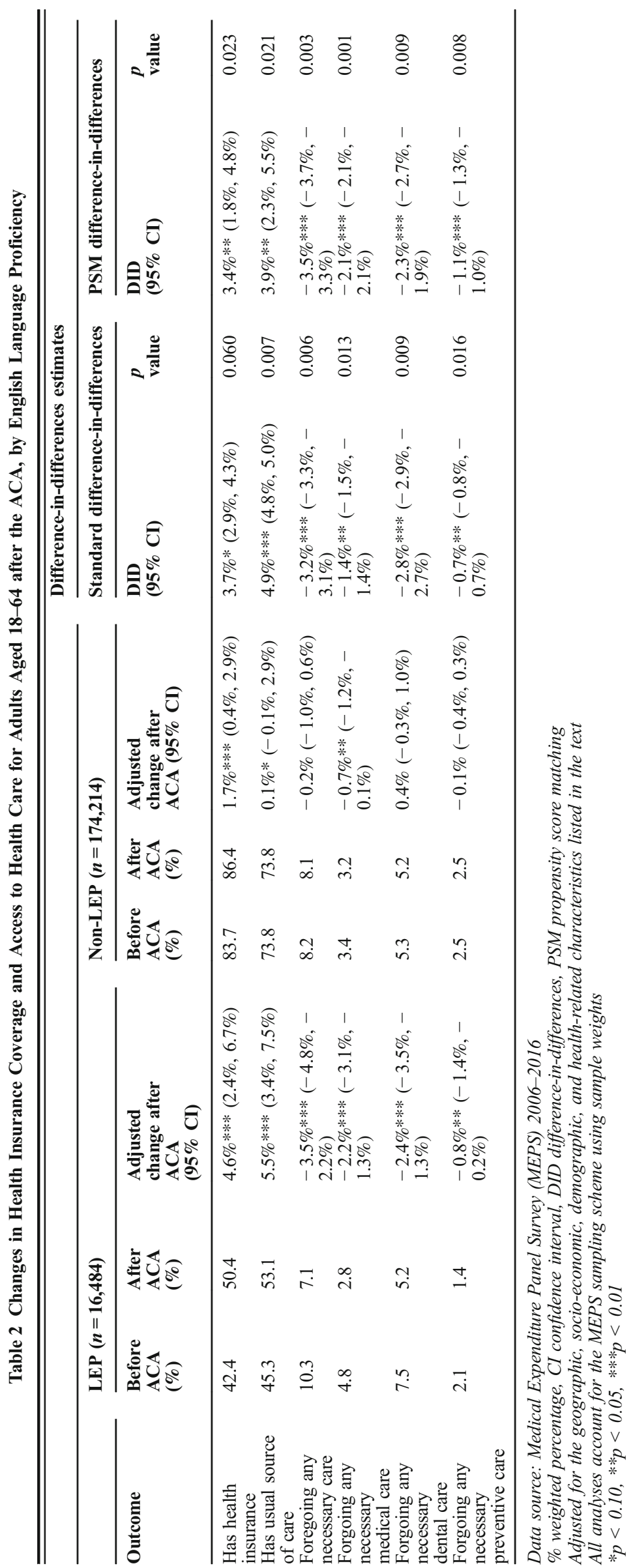


groups diminished after enactment of the $\mathrm{ACA}^{52-55}$ and evidence that patient-provider communication gaps by LEP improved after enactment of the ACA. ${ }^{40}$

Our results speak to a larger point in health policy: while a large research literature has connected increases in health insurance coverage with increases in access to care, access to care can also be improved by methods other than provision of insurance coverage. For people with LEP, lack of available translation is a particularly salient barrier to care. Language ability is relevant to health care access not only at the point of care but also in the health care seeking process (e.g., navigating the complexities of the health care system to find an innetwork provider, understanding cost sharing provisions, and seeking the appropriate appointments or referrals). A number of provisions of the ACA were relevant to people with LEP, underscoring the plausibility of our results. These included the revision of national Cultural and Linguistically Appropriate Service (CLAS) standards to boost health care access among people with LEP; requirements for insurance companies to provide translated documents in the languages of the local LEP community; and funding for health care provider training in cultural competence. ${ }^{39,41}$

The changes in disparities which we measure capture not only the effects of ACA policies but also other concurrent changes that affect people differently by their English language proficiency. If these concurrent changes were relatively unfavorable to people with LEP, such as intensification of immigration enforcement, then our data would capture a lower bound of the effect of ACA policies on disparities in coverage and access to care. Nonetheless, the possibility of such concurrent changes limits our ability to infer the causes of the changes in national trends we observe.

This study had limitations. The ACA provisions relevant to people with LEP were implemented at various dates in 2010 and later, preventing our analysis from teasing out the effects of specific policies. Additionally, the questions about selfreported confidence in speaking English in MEPS changed slightly over our sample period, although the meaning of the question remained quite similar (asking how well participants spoke English, vs. whether they felt comfortable speaking English in general). We also categorized participants based on whether a language other than English was spoken in their home, a question which remained the same throughout the sample period. Finally, MEPS did not distinguish citizens, non-citizens, and undocumented immigrants. Even though we limited our sample to US-born citizens and foreign-born people who have lived in the U.S. for more than 5 years, we were unable to exclude undocumented immigrants from our analysis, who were not eligible for Medicaid or insurance plans through the marketplace. Nonetheless, our matched analysis was more successful in restricting the sample to people with limited vs. high English proficiency who were similar in demographic and socio-economic characteristics, and the findings from the matched and unmatched analyses were similar.
In summary, this study provides new evidence of recent improvements in health care access and reduction in disparities in health care access by English proficiency among US population and documents improvements in coverage for people with high and low English proficiency. It offers insights into the changes that occurred for this important population after the ACA.

\section{Acknowledgments:}

The authors are grateful to Geoffrey Joyce, John Romley, Steven Fox, Emma Aguila, and three anonymous referees for helpful comments.

Data Availability Statement: The datasets analyzed in this study are available in the Medical Expenditure Panel Survey repository, at https://meps.ahrq.gov/data_stats/download_data_files.jsp

Corresponding Author: Rebecca Myerson, PhD; University of Wisconsin School of Medicine and Public Health, Madison, WI, USA (e-mail: rmyerson@wisc.edu).

\section{Compliance with Ethical Standards:}

The study was approved by the University of Southern California Institutional Review Board.

Conflict of Interest: The authors declare no conflicts of interest.

\section{REFERENCES}

1. Ryan C. Language use in the United States: 2011. American Community Survey Report 2013;22:1-16.

2. Zong J, Batalova J. The Limited English Proficient Population in the United States. Washington, DC: Migration Policy Institute; 2015. http:// curry.virginia.edu/uploads/resourceLibrary/MPI_Report_2015.pdf.

3. Caesar LG. English Proficiency and Access to Health Insurance in Hispanics Who Are Elderly: Implications for Adequate Health Care. Hisp J Behav Sci 2006;28(1):143-152. doi:https://doi.org/10.1177/ 0739986305284018

4. Gonzales G. State Estimates of Limited English Proficiency (LEP) by Health Insurance Status. The State Health Access Data Assistance Center (SHADAC); 2014

5. Ponce NA, Hays RD, Cunningham WE. Linguistic Disparities in Health Care Access and Health Status Among Older Adults. J Gen Intern Med 2006;21(7):786-791. doi:https://doi.org/10.1111/j.1525-1497.2006. 00491.x

6. Cheng EM, Chen A, Cunningham W. Primary Language and Receipt of Recommended Health Care Among Hispanics in the United States. J Gen Intern Med 2007;22(Suppl 2):283-288. doi:https://doi.org/10.1007/ s11606-007-0346-6

7. DuBard CA, Gizlice Z. Language Spoken and Differences in Health Status, Access to Care, and Receipt of Preventive Services Among US Hispanics. Am J Public Health 2008;98(11):2021-2028. doi:https://doi. org/10.2105/AJPH.2007.119008

8. Brach C, Chevarley FM. Demographics and Health Care Access and Utilization of Limited-English-Proficient and English-Proficient Hispanics. Agency for Healthcare Research and Quality; 2008.

9. Shi L, Lebrun LA, Tsai J. The influence of English proficiency on access to care. Ethn Health 2009;14(6):625-642. doi:https://doi.org/10.1080/ 13557850903248639

10. Smith D. Health Care Disparities for Persons with Limited English Proficiency: Relationships from the 2006 Medical Expenditure Panel Survey (MEPS). J Health Dispar Res Pract. 2012;3(3). https://digitalscholarship.unlv.edu/jhdrp/vol3/iss3/4

11. Lebrun LA. Effects of length of stay and language proficiency on health care experiences among immigrants in Canada and the United States. Soc Sci Med 1982. 2012;74(7):1062-1072. doi:https://doi.org/10.1016/ j.socscimed.2011.11.031

12. Weech-Maldonado $\mathbf{R}$, Morales LS, Elliott M, Spritzer K, Marshall G, Hays RD. Race/Ethnicity, Language, and Patients' Assessments of Care 
in Medicaid Managed Care. Health Serv Res 2003;38(3):789-808. doi:https://doi.org/10.1111/1475-6773.00147

13. Divi C, Koss RG, Schmaltz SP, Loeb JM. Language proficiency and adverse events in US hospitals: a pilot study. Int $\mathrm{J}$ Qual Health Care 2007;19(2):60-67. doi:https://doi.org/10.1093/intqhc/mzl069

14. Pippins JR, Alegria $\mathbf{M}$, Haas JS. Association Between Language Proficiency and the Quality of Primary Care Among A National Sample of Insured Latinos. Med Care 2007;45(11):1020-1025. doi:https://doi. org/10.1097/MLR.0b013e31814847be

15. Morales LS, Cunningham WE, Brown JA, Liu H, Hays RD. Are Latinos Less Satisfied with Communication by Health Care Providers? J Gen Intern Med 1999;14(7):409-417. doi:https://doi.org/10.1046/j.15251497.1999.06198.x

16. Wilson E, Chen AH, Grumbach K, Wang F, Fernandez A. Effects of Limited English Proficiency and Physician Language on Health Care Comprehension. J Gen Intern Med 2005;20(9):800-806. doi:https://doi. org/10.1111/j.1525-1497.2005.0174.x

17. Flores G. Language barriers to health care in the United States. N Engl J Med 2006;355(3):229-231. doi:https://doi.org/10.1056/NEJMp058316

18. Lopez-Quintero C, Berry EM, Neumark Y. Limited English Proficiency Is a Barrier to Receipt of Advice about Physical Activity and Diet among Hispanics with Chronic Diseases in the United States. J Am Diet Assoc 2009;109(10):1769-1774. doi:https://doi.org/10.1016/j.jada.2009.07. 003

19. Karliner LS, Auerbach A, Nápoles A, Schillinger D, Nickleach D, Pérez-Stable EJ. Language Barriers and Understanding of Hospital Discharge Instructions. Med Care 2012;50(4):283-289. doi:https://doi. org/10.1097/MLR.0b013e318249c949

20. Woloshin S, Schwartz LM, Katz SJ, Welch HG. Is Language a Barrier to the Use of Preventive Services? J Gen Intern Med 1997;12(8):472-477. doi:https://doi.org/10.1046/j.1525-1497.1997.00085.x

21. Jacobs EA, Karavolos K, Rathouz PJ, Ferris TG, Powell LH. Limited English proficiency and breast and cervical cancer screening in a multiethnic population. Am J Public Health 2005;95(8):1410-1416. doi:https://doi.org/10.2105/AJPH.2004.041418

22. Diaz JA, Roberts MB, Goldman RE, Weitzen S, Eaton CB. Effect of Language on Colorectal Cancer Screening Among Latinos and NonLatinos. Cancer Epidemiol Biomark Prev Publ Am Assoc Cancer Res Cosponsored Am Soc Prev Oncol 2008;17(8):2169-2173. doi:https://doi. org/10.1158/1055-9965.EPI-07-2692

23. Wallace SP, Gutiêrrez VF, Castañeda $\mathbf{X}$. Access to preventive services for adults of Mexican origin. J Immigr Minor Health 2008;10(4):363-371. doi:https://doi.org/10.1007/s10903-007-9093-3

24. Pearson WS, Zhao G, Ford ES. An Analysis of Language as a Barrier to Receiving Influenza Vaccinations among an Elderly Hispanic Population in the United States. Adv Prev Med 2011;2011. https://doi.org/10.4061/ $2011 / 298787$

25. Masland MC, Kang SH, Ma Y. Association between limited English proficiency and understanding prescription labels among five ethnic groups in California. Ethn Health 2011;16(2):125-144. doi:https://doi. org/10.1080/13557858.2010.543950

26. Wisnivesky JP, Krauskopf $\mathbf{K}$, Wolf $\mathbf{M S}$, et al. The association between language proficiency and outcomes of elderly patients with asthma. Ann Allergy Asthma Immunol 2012;109(3):179-184. doi:https://doi.org/10. 1016/j.anai.2012.06.016

27. Moreno G, Lin EH, Chang E, et al. Disparities in the Use of Internet and Telephone Medication Refills among Linguistically Diverse Patients. J Gen Intern Med 2016;31(3):282-288. doi:https://doi.org/10.1007/s11606015-3500-6

28. Fernandez A, Schillinger D, Warton EM, et al. Language barriers, physician-patient language concordance, and glycemic control among insured Latinos with diabetes: The diabetes study of Northern California (DISTANCE). J Gen Intern Med 2011;26(2):170-176. doi:https://doi.org/ 10.1007/s11606-010-1507-6

29. Kim G, Aguado Loi CX, Chiriboga DA, Jang Y, Parmelee P, Allen RS Limited English proficiency as a barrier to mental health service use: a study of Latino and Asian immigrants with psychiatric disorders. J Psychiatr Res 2011;45(1):104-110. doi:https://doi.org/10.1016/j.jpsychires.2010.04.031

30. Wisnivesky JP, Kattan M, Evans D, et al. Assessing the relationship between language proficiency and asthma morbidity among inner-city asthmatics. Med Care 2009;47(2):243-249. doi:https://doi.org/10. 1097/MLR.0b013e3181847606

31. Kim EJ, Kim T, Paasche-Orlow MK, Rose AJ, Hanchate AD. Disparities in Hypertension Associated with Limited English Proficiency. J Gen
Intern Med 2017;32(6):632-639. doi:https://doi.org/10.1007/s11606017-3999-9

32. Njeru JW, St. Sauver JL, Jacobson DJ, et al. Emergency department and inpatient health care utilization among patients who require interpreter services. BMC Health Serv Res 2015;15(1):214. doi:https:// doi.org/10.1186/s12913-015-0874-4

33. Ngai KM, Grudzen CR, Lee R, Tong VY, Richardson LD, Fernandez A. The Association between Limited English Proficiency and Unplanned Emergency Department Revisit within 72 hours. Ann Emerg Med 2016;68(2):213-221. doi:https://doi.org/10.1016/j.annemergmed. 2016.02 .042

34. John-Baptiste A, Naglie G, Tomlinson G, et al. The Effect of English Language Proficiency on Length of Stay and In-hospital Mortality. J Gen Intern Med 2004;19(3):221-228. doi:https://doi.org/10.1111/j.15251497.2004.21205.x

35. López L, Rodriguez F, Huerta D, Soukup J, Hicks L. Use of interpreters by physicians for hospitalized limited English proficient patients and its impact on patient outcomes. J Gen Intern Med 2015;30(6):783-789. doi:https://doi.org/10.1007/s11606-015-3213-x

36. Lindholm M, Hargraves JL, Ferguson WJ, Reed G. Professional language interpretation and inpatient length of stay and readmission rates. J Gen Intern Med 2012;27(10):1294-1299. doi:https://doi.org/10. 1007/s11606-012-2041-5

37. Hines AL, Andrews RM, Moy E, Barrett ML, Coffey RM. Disparities in Rates of Inpatient Mortality and Adverse Events: Race/Ethnicity and Language as Independent Contributors. Int J Environ Res Public Health 2014;11(12):13017-13034. doi:https://doi.org/10.3390/ ijerph 111213017

38. Tang EW, Go J, Kwok A, et al. The relationship between language proficiency and surgical length of stay following cardiac bypass surgery. Eur J Cardiovasc Nurs 2016;15(6):438-446. doi:https://doi.org/10. $1177 / 1474515115596645$

39. U.S. Government. Affordable Care Act \& 1557 : 2010.

40. Berdahl TA, Kirby JB. Patient-Provider Communication Disparities by Limited English Proficiency (LEP): Trends from the US Medical Expenditure Panel Survey, 2006-2015. J Gen Intern Med 2018. doi:https://doi. org/10.1007/s11606-018-4757-3

41. Somers S, Mahadevan R. Health Literacy Implications of the Affordable Care Act. Center for Health Care Strategies; 2010.

42. National CLAS Standards: Fact Sheet. https://www.thinkculturalhealth. hhs.gov/pdfs/NationalCLASStandardsFactSheet.pdf.

43. Agency for Healthcare Research and Quality. MEPS-HC Response Rates by Panel.; 2018.

44. Centers for Medicare \& Medicaid Service. Eligibility for Non-Citizens in Medicaid and CHIP.; 2014. https://www.medicaid.gov/medicaid/outreach-and-enrollment/downloads/overview-of-eligibility-for-non-citizens-in-medicaid-and-chip.pdf.

45. Bureau UC. About Language Use in the U.S. Population. https://www. census.gov/topics/population/language-use/about.html. Accessed 19 June 2019.

46. Bertrand M, Duflo E, Mullainathan S. How Much Should We Trust Differences-in-Differences Estimates? Q J Econ 2004;119(1):249-275. doi:https://doi.org/10.3386/w8841

47. Austin PC. An Introduction to Propensity Score Methods for Reducing the Effects of Confounding in Observational Studies. Multivar Behav Res 2011;46(3):399-424. doi:https://doi.org/10.1080/00273171.2011. 568786

48. Normand ST, Landrum MB, Guadagnoli E, et al. Validating recommendations for coronary angiography following acute myocardial infarction in the elderly: a matched analysis using propensity scores. J Clin Epidemiol 2001;54(4):387-398. doi:https://doi.org/10.1016/s0895-4356(00) 00321-8

49. Karaca-Mandic $\mathbf{P}$, Norton EC, Dowd B. Interaction Terms in Nonlinear Models. Health Serv Res. 2012;47(1pt1):255-274. doi:https://doi.org/ 10.1111/j.1475-6773.2011.01314.x

50. Johnson HM, Thorpe CT, Bartels CM, et al. Undiagnosed hypertension among young adults with regular primary care use. J Hypertens 2014;32(1):65-74. doi:https://doi.org/10.1097/HJH. 0000000000000008

51. Eamranond PP, Patel KV, Legedza ATR, Marcantonio ER, Leveille SG. The association of language with prevalence of undiagnosed hypertension among older Mexican Americans. Ethn Dis 2007;17(4):699-706.

52. Sommers BD, Gunja MZ, Finegold $\mathbf{K}$, Musco T. Changes in Selfreported Insurance Coverage, Access to Care, and Health Under the Affordable Care Act. JAMA. 2015;314(4):366-374. doi:https://doi.org/ 10.1001/jama.2015.8421 
53. Wherry LR, Miller S. Early Coverage, Access, Utilization, and Health Effects Associated With the Affordable Care Act Medicaid Expansions: A Quasi-experimental Study. Ann Intern Med 2016;164(12):795. doi:https://doi.org/10.7326/M15-2234

54. Miller S, Wherry LR. Health and Access to Care during the First 2 Years of the ACA Medicaid Expansions. N Engl J Med 2017;376(10):947-956. doi:https://doi.org/10.1056/NEJMsa1612890
55. Chen J, Vargas-Bustamante A, Mortensen K, Ortega AN. Racial and ethnic disparities in health care access and utilization under the affordable care act. Med Care 2016;54(2):140-146. doi:https://doi.org/ 10.1097/MLR.0000000000000467

Publisher's Note Springer Nature remains neutral with regard to jurisdictional claims in published maps and institutional affiliations. 